\title{
Sex Differences in Oral Health and the Consumption of Sugary Diets in a Saudi Arabian Population
}

\author{
Abdulrahman K Alkhaldi (iD' \\ Hamad Alshiddi ${ }^{2}$ \\ Mansour Aljubair ${ }^{3}$ \\ Saad Alzahrani ${ }^{4}$ \\ Adel Alkhaldi ${ }^{5}$ \\ Khalifa S Al-khalifa (iD ${ }^{6}$ \\ Balgis Gaffar (iD) \\ 'Ministry of Health, Tabuk, Kingdom of \\ Saudi Arabia; ${ }^{2}$ Majal Dental Center, \\ Alkhobar, Kingdom of Saudi Arabia; \\ ${ }^{3}$ Ministry of Health, Dammam, Kingdom \\ of Saudi Arabia; ${ }^{4}$ RAM Dental Clinics, \\ Dammam, Kingdom of Saudi Arabia; \\ ${ }^{5}$ College of Dentistry, Imam \\ Abdulrahman Bin Faisal University, \\ Dammam, Kingdom of Saudi Arabia; \\ ${ }^{6}$ Department of Preventive Dental \\ Sciences, College of Dentistry, Imam \\ Abdulrahman Bin Faisal University, \\ Dammam, Kingdom of Saudi Arabia
}

Correspondence: Balgis Gaffar Department of Preventive Dental Sciences, College of Dentistry, Imam Abdulrahman Bin Faisal University,

Dammam Costal Street, - B.O Box 1982 ,

Dammam, 3|44I, Saudi Arabia

Tel +96654226994l

Email bgosman@iau.edu.sa
Background and Purpose: Adolescence is a crucial period for developing healthy lifestyle and dietary habits. The growing consumption of high-sugar foods and beverages constitutes a serious public health concern. The aim of this study was to evaluate sex differences in the consumption of a sugary diet and oral health among Saudi adolescents.

Subjects and Methods: This cross-sectional study was conducted in the Eastern Province of the Kingdom of Saudi Arabia between January and February 2019. A multistage sampling technique was used to recruit 2265 middle-school children aged 12-16 years. Data were collected via the Food Frequency Questionnaire and via an oral health examination, using the WHO criteria. The chi-squared test, Student's $t$-test, and Mann-Whitney $U$-test were used to investigate the associations between the study variables.

Results: The most consumed foods and beverages reported were water, juices, and biscuits (90\%), while the least consumed were energy drinks and jams. A significant difference was found between males and females in the frequency of consumed sugary foods $(\mathrm{P}=0.01)$ and the quantity of consumed sugary beverages $(\mathrm{P}=0.000)$; males over all consumption were greater than their counterpart. However, no differences were found between sexes in the frequency of sugary drink consumption $(\mathrm{P}=0.2)$. The decayed-missing-filled index score was significantly higher in females $(4.29 \pm 3.44)$ than in males $(3.61 \pm 3.14 ; \mathrm{P}=0.001)$. The mean plaque index among males and females was $1.72( \pm 0.79)$ and $1.20( \pm 0.78)$, respectively, while the mean gingival index was 1.31 $( \pm 0.77)$ in males and $0.69( \pm 0.73)$ in females - a statistically significant difference $(\mathrm{P}=0.001)$.

Conclusion: Sex differences were found in sugary diet consumption and oral health status. Thus, policy makers are encouraged to consider sex-based differences when planning preventative programs and initiatives. Nevertheless, further research is needed on the dietary intake patterns of young adults.

Keywords: adolescents, caries, sex, oral hygiene, sugar intake

\section{Introduction}

In many countries, the consumption of a diet high in sugar is a serious public health concern and has grown in popularity across all age-groups in recent years. ${ }^{1,2}$ Excess dietary sugar increases the risk for dental diseases, obesity and other metabolic conditions, cardiovascular diseases, and some cancers. ${ }^{3}$ Additionally, the relationship between oral health and general health is well established in the literature. ${ }^{4}$ Indeed, many systemic diseases and conditions have oral manifestations ${ }^{5}$ similarly, oral health conditions may lead to, or exacerbate the severity of, certain medical conditions. ${ }^{6}$ 
The World Health Organization (WHO) reports that dental caries is the most common non-communicable disease worldwide. ${ }^{7}$ Dental caries is a multi-factorial disease of the hard dental tissue that begins with demineralization of the enamel and progresses to irreversible stages, such as cavitation and pulpal involvement. ${ }^{8}$ The presence of bacteria, a cariogenic diet, and the host's features are the main caries risk factors. ${ }^{9}$ Gingivitis refers to inflammation of the soft tissue surrounding the tooth, which may progress to periodontitis, in which the connective tissue supporting the tooth becomes damaged, potentially leading to tooth mobility and, eventually, tooth loss. ${ }^{10}$

A study on the prevalence of dental diseases reported factors such as differences in saliva composition, hormones, dietary habits, genetic variations, and sociobehavioral factors as possible contributors to caries risk. ${ }^{11,12}$ Although caries is found more frequently among females, better gingival and periodontal health are also more commonly found in women. ${ }^{12}$ Indeed, females report more positive dental health attitudes and better oral health behaviors. ${ }^{12}$ Conversely, a recent study from Romania found that caries prevalence was lower among females, who were also found to have better oral hygiene practices and more regular dental visits; however, the consumption of sugar-sweetened beverages was found to be significantly higher among males. ${ }^{13}$ Similarly, a study from the Kingdom of Saudi Arabia (KSA) found that females had better oral hygiene practices, more dental visits and treatments, and a greater daily consumption of refined carbohydrates relative to males. ${ }^{14}$ Another study from the KSA found that males snack more often and consume more sweets than females. ${ }^{15}$

Young adults in the KSA suffer from a high prevalence of dental caries and gingivitis and has seen an alarming rise in obesity rates. ${ }^{2}$ However, few studies to date have assessed the dietary habits and nutritional preferences of Saudi populations, especially among school-aged children and adolescents. Since the 1980s, the WHO has encouraged the analysis of sex differences in all areas of medicine and greater attention being paid to women's health. ${ }^{16}$ Relevant studies from the KSA mainly assessed sex differences in beliefs, behaviors, or perceptions; however, supplementation of these variables with actual oral health status remains lacking in the KSA.

Adolescence is a crucial period for developing healthy lifestyle practices and dietary habits. The consequences of poor oral health and increased consumption of a diet high in processed sugar among adolescents is detrimental not only to their physical health, but also to social and economic well-being. As part of the customs of Saudi society, health programs target males and females separately; thus, understanding the sex differences in oral health status and in dietary intake can help guide policymakers in designing preventive and interventional programs. Therefore, this study aimed to determine sex differences in the frequency and quantity of sugar consumption and in the oral health status of middle school students in the Eastern Province of the KSA.

\section{Subjects and Methods}

This cross-sectional study was conducted in the Eastern Province of the KSA between January and February 2019. Males and females in public secondary schools were targeted using a multistage sampling technique. Firstly, schools were randomly selected by a draw from a list provided by the Ministry of Education. The selection process aimed to adequately represent the geographical areas within the major cities (Dammam, Khobar, Dhahran, and Al-Qatif) of the Eastern Province.

The ministry of education assigns the schools as belonging to one of several regional offices. The number of schools in each regional office varies according to the size of the city, ranging from more than 100 schools in larger cities, such as Dammam, to 10 in smaller cities. Two regional offices were randomly selected from big geographical areas, while one was chosen from smaller areas. Secondly, a simple random technique (random selection from list) was used to randomly select schools depending on the size of the city and stratified by sex. For example, six schools (three all-male and three all-female schools) were selected from Dammam regional offices, whereas two schools (one all-male and one all-female school) from Dhahran.

Within each school, the school administrators randomly assigned classes for the examination. Within the classes, the names of all eligible students were listed and randomly selected. A simple draw was used to randomly select classes as well as the eligible students within those classes (classes and students names were written on a piece of paper and put in a container one for classes and one for names; and one of the research team picked the names manually). Figure 1 displays the participant recruitment process. Ultimately, 16 schools were included, encompassing an initial 3411 students. Following application of the inclusion and exclusion criteria, a total of 2911 
6 schools in Dammam (3 male's / 3 female's) $+$

4 schools in Khobar (2 male's / 2 female's) $+$

4 schools in Al-Qatif (2 male's / 2 female's) $+$

2 schools in Dhahran (1 male's / 1 female's)

Total $=16$ schools

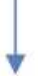

Total number of students in 16 schools

$=3,411$

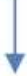

Total number of eligible students based on inclusion and exclusion criteria $=2,911$

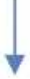

Total number of students who provided

consent

\section{$=2,265$ (response rate $77.8 \%)$}

Figure I Flow chart of participants' recruitment process.

students were eligible to participate in the study, of whom 2265 provided consent.

The independent variable in our study was the sex of the student, whereas the dependent variables were the frequency and quantity of beverages (water, milk, sweet milk, soft drinks, juices, and energy drinks) and foods (biscuits, chewing gum containing sugar, candies, and jams) as well as the oral health status of participants (plaque accumulation, gingival inflammation, and dental caries).

Data were collected through an oral health examination and through a questionnaire that collected biodata (parental education levels) and information on oral health practices (dental visits and brushing habits). Information about dietary practices was collected using the food frequency questionnaire (FFQ), a tool that has been validated for use in both adolescents and adults in the KSA. ${ }^{17-19}$ The FFQ was administered in the form of an interview. The participants were interviewed in Arabic, and each interview lasted between 8-10 min. Participants were shown bottles and cans containing different volumes. Quantities were then categorized $(<300 \mathrm{~mL}$ vs $\geq 300 \mathrm{~mL})$ and the frequency of consumption was categorized (never, monthly, weekly and daily). Candies included all hard sweets made from flavored crystallized sugar; jams included condiments made from pressed fruits and sugar; juices referred to all fruit- and vegetable drinks containing added sugar; and energy drinks referred to beverages (carbonated or uncarbonated) containing high levels of stimulants, refined sugars, and supplements.

Oral health examinations were performed by five examiners, who were calibrated with a gold standard $(\mathrm{K}=0.79)$. Examinations were performed according to the WHO criteria; with a disposable mouth mirror in daylight. ${ }^{21}$ Well-known epidemiological indices, namely, the DMFT (Decayed, Missing due to caries, and Filled Teeth) index for dental caries, the plaque index (PI) to assess the accumulation of plaque, and the gingival index (GI) to assess the degree of gingival inflammation. ${ }^{20,21}$ Dental caries were recorded first, followed by assessment of plaque accumulation and gingival condition.

Teeth with cavities were recorded as decayed, as were broken and temporary fillings. Teeth with intact permanent fillings were recorded as filled. Only missing teeth due to caries were recorded as missed, while teeth extracted for any other reason were excluded. The DMFT index of a participant was the sum of the number of decayed, missed, and filled teeth. The mean DMFT value was the sum of participants' individual DMFT values divided by the total number of students examined. ${ }^{20}$

The GI assessed qualitative changes in the gingiva, namely, redness, swelling, and gingival bleeding. Gingival redness and swelling were assessed visually, whereas gingival bleeding was assessed using a specialized probe (WHO periodontal probe) inserted in the gingival sulcus. ${ }^{21}$ For field studies, four sites of six teeth (index teeth) are usually examined, and each site is given a score from zero to three. The GI was scored as follows: $0=$ healthy gingiva; $1=$ mild inflammation (slight change in color and slight edema, but no bleeding on probing); 2 = moderate inflammation (redness, edema and glazing, bleeding on probing); $3=$ severe inflammation (marked redness and edema, ulceration with tendency to bleed spontaneously). The scores of the four tooth areas 
were summed and divided by four to obtain the GI for the tooth. The GI of each participant was obtained by adding the values of each tooth and dividing this value by the number of teeth examined. ${ }^{21}$

The PI follows the same scoring criteria as the GI; however, plaque accumulation was visually assessed on the gingival third (margin) of the tooth. Plaque was scored as follows: $0=$ no plaque; $1=$ adherence of a film of plaque to the free gingival margin and adjacent area of the tooth; 2 = moderate accumulation of soft deposit within the tooth margin that can be seen with the naked eye; $3=$ abundance of soft matter within the tooth margin. ${ }^{21}$

Participants were included if they were between the ages of 12 and 14 years, were regular attendees of the school, obtained consent from their parents or legal guardians, and agreed to be examined and interviewed. Participants with medical problems or special needs were excluded.

The study was conducted in accordance with the Declaration of Helsinki and was approved by the Deanship of Scientific Research (IRB-2015-02-187) Imam Abdulrahman bin Faisal University, Dammam, Saudi Arabia. A written informed consent form was attached to the questionnaire, along with a cover letter explaining the purpose of the study and the type of data to be collected. Written informed consents were obtained from participants' parents before commencing with the study.
Statistical analyses were performed with SPSS (v. 23), and the descriptive data were presented as frequency (percentage) and mean (standard deviation). Associations between dependent and independent variables were examined using the $\chi^{2}$ test, the Student's $t$-test, and the MannWhitney $U$-test (for non-normally distributed data sets). A $P$ of $<0.05$ was considered statistically significant.

\section{Results}

A total of 2265 out of 2911 eligible middle school students were included in the study, representing a response rate of $77.8 \%$. Fewer than half of the participants were males $(43 \%)$, and the mean age of the sample was $14( \pm 1.24)$ years. The majority of the participants' parents had only a school education.

Regarding dental visits, $45 \%$ of female respondents visited the dentist more than once per year, compared to only $35 \%$ of male respondents. Furthermore, the majority of females respondents $(68 \%)$ reported brushing their teeth twice daily, compared to only $29 \%$ of male respondents. (Table 1).

The overall mean $( \pm \mathrm{SD})$ DMFT value was higher in females (4.29 \pm 3.44) than in males (3.61 \pm 3.14 ; $\mathrm{P}<0.001)$. Females had more DMFT compared to males, with differences in missing and filled teeth being statistically significant $(\mathrm{P}=0.001$ and $\mathrm{P}<0.001$, respectively); however, this was not the case for the mean decayed teeth $(\mathrm{P}=0.247$; Table 2$)$. The mean $\mathrm{PI}$ was higher in

Table I Distribution of Study Variables Between Males and Females

\begin{tabular}{|c|c|c|c|}
\hline & & Male & Female \\
\hline \multicolumn{2}{|l|}{ Participants N (\%) } & $977(43.1 \%)$ & $1288(56.9 \%)$ \\
\hline \multicolumn{2}{|l|}{ Age Mean $( \pm S D)$} & $14( \pm 1.51)$ & $14( \pm 0.98)$ \\
\hline Father's education & Illiterate & 81 (8.3\%) & $|2|(9.4 \%)$ \\
\hline \multirow[t]{2}{*}{$N(\%)$} & School educated & $487(49.8 \%)$ & $624(48.4 \%)$ \\
\hline & Higher educated & 409 (4I.9\%) & $543(42.2 \% \mid)$ \\
\hline \multirow[t]{3}{*}{ Mother's education N (\%) } & Illiterate & $103(10.5 \%)$ & $|2|(9.4 \%)$ \\
\hline & School educated & $54 \mathrm{I}(55.4 \%)$ & $684(53.1 \%)$ \\
\hline & Higher educated & $333(34.1 \%)$ & $483(37.5 \%)$ \\
\hline \multirow[t]{3}{*}{ Dental visits per year N (\%) } & Never & $44 \mid(45.1 \%)$ & $520(40.4 \%)$ \\
\hline & Once & $198(20.3 \%)$ & $194(15.1 \%)$ \\
\hline & More than once & $338(34.6 \%)$ & $574(44.6 \%)$ \\
\hline \multirow[t]{3}{*}{ Brushing frequency per day $\mathrm{N}(\%)$} & Never & $123(12.6 \%)$ & $13(1.0 \%)$ \\
\hline & Once or less & $572(58.5 \%)$ & $404(31.4 \%)$ \\
\hline & Twice & $282(28.9 \%)$ & $87 \mid(67.6 \%)$ \\
\hline
\end{tabular}

Abbreviations: N, number; SD, standard deviation. 
Table 2 Sex Differences in Relation to Mean Scores of DMF, Gingival Index and Plaque Index

\begin{tabular}{|l|c|c|c|}
\hline & Male & Female & P-value \\
\hline DMF Mean ( \pm SD) & $3.61( \pm 3.14)$ & $4.29( \pm 3.44)$ & $<0.00 I^{*}$ \\
- Decayed Mean $( \pm S D)$ & $3.01( \pm 2.90)$ & $3.24( \pm 3.17)$ & 0.247 \\
- Missing Mean $( \pm S D)$ & $0.16( \pm 0.58)$ & $0.31( \pm 1.04)$ & $0.00 I^{*}$ \\
- Filled Mean $( \pm S D)$ & $0.43( \pm 1.01)$ & $0.74( \pm 1.45)$ & $<0.00 I^{*}$ \\
Plaque index Mean $( \pm S D)$ & $1.72( \pm 0.79)$ & $1.20( \pm 0.78)$ & $<0.00 I^{*}$ \\
Gingival index Mean ( $\pm S D)$ & $1.31( \pm 0.77)$ & $0.69( \pm 0.73)$ & $<0.00 I^{*}$ \\
\hline
\end{tabular}

Notes: Significance test (Mann-Whitney $U$-test). $P$ value $<0.05$ is considered statistically significant. *Statistically significant.

Abbreviation: SD, standard deviation.

males $(1.72 \pm 0.79)$ than in females $(1.20 \pm 0.78)$. Likewise for the mean GI, which was $1.31( \pm 0.77)$ in males and $0.69( \pm 0.73)$ in females. The means of the PI and GI were statistically significant (Table 2).

Table 3 shows that the mean frequency of consumed sugary foods was $11.7( \pm 2.2)$ for males and $11.5( \pm 2.3)$ for females $(\mathrm{P}=0.010)$. However, the mean frequency of consumed sugary drinks was nearly identical between males and females $(9.7 \pm 2.2$ and $9.6 \pm 2.4$, respectively). Furthermore, males were found to consume significantly greater overall quantities of sugary drinks $(8 \pm 1.4)$ relative to females $(7.5 \pm 1.5 ; \mathrm{P}=0.000$; Table 3$)$.

Regarding the frequency of sugary-food consumption, the most frequently consumed product was cookies and the least consumed was jams (Figure 2). A statistically significant difference was found in the frequency of consuming sugary food between males and females: females consumed more cookies $(47.3 \%)$, sugar-containing chewing gums $(46.7 \%)$, and candies $(47.5 \%)$ on a daily basis. On the other hand, the daily consumption of jams was greater among males (17.9\%; $\mathrm{P}=0.000$; Table 4).

The beverages consumed in the greatest quantities were water and juices, whereas energy drinks were the least consumed (Figure 2). The majority of participants reported consuming more than $300 \mathrm{~mL}$ of water daily, while $51 \%$ reported consuming more than $300 \mathrm{~mL}$ of soft drinks daily (Figure 3 ). The daily consumption of juices $(58.6 \%)$ and soft drinks $(23.7 \%)$ was significantly greater among males $(\mathrm{P}=0.000)$, whereas females consumed more sweetened milk $(25.3 \% ; \mathrm{P}=0.000)$ and energy drinks (4.1\%; $\mathrm{P}=0.349$; Table 4).

When investigating the difference in the quantity of drinks consumed, $60 \%$ of males consumed the larger volume $(>300 \mathrm{~mL})$ of soft drinks, while $44 \%$ of females consumed the larger volume. Males consumed larger quantities of all sugary drinks on a daily basis, except for energy drinks, which were consumed in larger quantities by females (Table 5). Greater quantities $(>300 \mathrm{~mL})$ of juices were consumed by males $(35.6 \%)$ than by females $(13.4 \%)$, as was the case for quantities of soft drinks (60.2\% and $44.1 \%$ for males and females, respectively) as well as sweetened milk $(\mathrm{P}=0.000$; Table 5). Surprisingly, females consumed greater quantities of energy drinks ( $8 \%$ vs $6.4 \% ; \mathrm{P}=0.000)$. Males consumed slightly greater quantities of sweetened milk than females (11.9\% vs $9 \% ; \mathrm{P}=0.000$; Table 5).

\section{Discussion}

This study supports the existence of sex differences in oral health status and in the consumption of sugar-containing

Table 3 Sex Differences in Relation to the Overall Consumption of Sugary Food and Beverages

\begin{tabular}{|c|c|c|c|c|}
\hline & Sex & $\mathbf{N}$ & Mean \pm SD & P-value \\
\hline Overall frequency of sugary food ${ }^{a}$ & $\begin{array}{l}\text { Male } \\
\text { Female }\end{array}$ & $\begin{array}{l}977 \\
1288\end{array}$ & $\begin{array}{l}11.7 \pm 2.2 \\
11.5+2.3\end{array}$ & $0.010 *$ \\
\hline Overall frequency of sugary drinks ${ }^{a}$ & $\begin{array}{l}\text { Male } \\
\text { Female }\end{array}$ & $\begin{array}{l}977 \\
1288\end{array}$ & $\begin{array}{l}9.7 \pm 2.2 \\
9.6 \pm 2.4\end{array}$ & 0.203 \\
\hline Overall quantity of sugary drinks ${ }^{b}$ & $\begin{array}{l}\text { Male } \\
\text { Female }\end{array}$ & $\begin{array}{c}977 \\
1288\end{array}$ & $\begin{array}{l}8.0 \pm 1.4 \\
7.5 \pm 1.5\end{array}$ & $0.000 *$ \\
\hline
\end{tabular}

Notes: Significance test (t- test). $P$ value $<0.05$ is considered statistically significant. *Statistically significant. ${ }^{\mathrm{a}}$ Total mean out of $16 .{ }^{\mathrm{b}}$ Total mean out of 12 . Abbreviation: SD, standard deviation. 


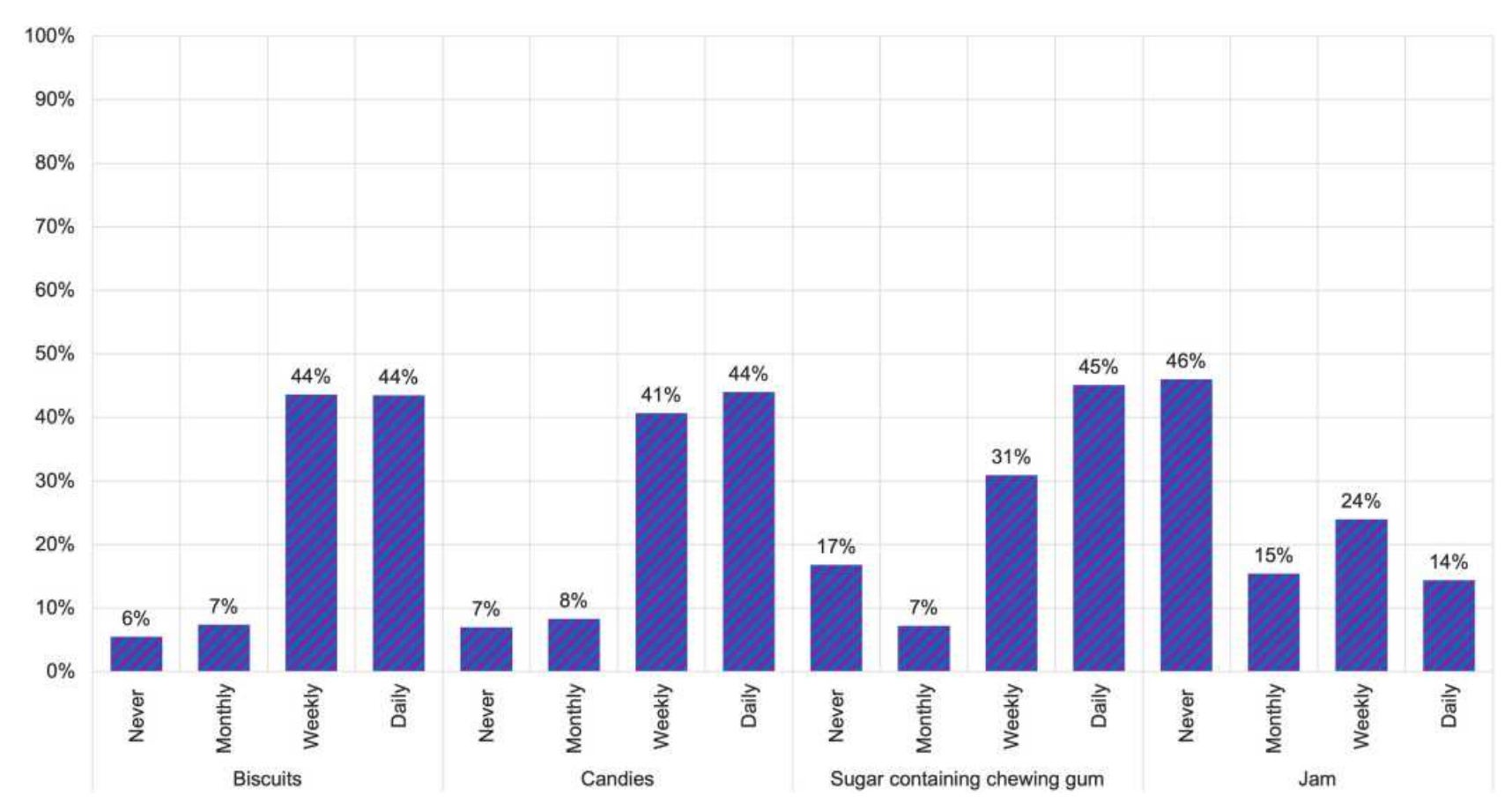

Figure 2 Quantity of the consumed drinks among the study sample.

foods and drinks. Females had higher DMFT values, while males were found to have more plaque accumulation and gingival problems; further, their total daily frequency of sugary food and beverage intake, as well as their overall quantities of drinks consumed, were higher than in females.

Additionally, the daily consumption of sugary foods was greater among females-except for jam-while overall weekly and monthly consumption was greater among males $(\mathrm{P} \leq 0.001)$. These findings aligned closely with those of a recent publication based on two national Lebanese surveys, whose authors reported that females reported significantly higher daily consumption of all sugary foods-including jams-than did males. ${ }^{22}$ Hormones and stress are two factors that have recently been proposed to explain the increased consumption of sugary foods among females. ${ }^{23}$

On the other hand, the daily intake of juices and soft drinks was higher among males, in line with the findings of multiple local and international studies. ${ }^{1,24}$ A previous study carried out in Riyadh, the capital city of KSA, reported that males consumed more soft drinks than did females, while sweetened milk consumption was greater among females. ${ }^{25}$ These results are in agreement with the findings of the present study. Sex differences in food consumption patterns has been attributed to social norms and cultural beliefs; for example, some foods are associated with masculinity, others with femininity. ${ }^{26}$ The finding that males consume a greater volume of soft drinks and energy drinks is not surprising given that males are traditionally perceived as more active and mobile in eastern societies.

An alarming finding was the low consumption of milk-in both frequency and quantity - among our study participants: plain milk was consumed daily by $41 \%$ of respondents, and with only $21 \%$ of them reported a daily intake exceeding $300 \mathrm{~mL}$. An Australian study also found a significant decrease in the total daily consumption of dairy products-milk, in particular-from ages 12 to 17 years. However, and contradicting our findings, they reported a more significant decline in milk consumption in girls than in boys. ${ }^{27}$

Milk is an important source of nutrients-especially calcium and vitamin $\mathrm{D}$, which are essential for healthy bones and teeth. Nearly $60 \%$ of the Saudi population suffer from deficiency in vitamin $\mathrm{D},{ }^{28}$ which is associated with oral immunity and the integrity of the periodontium. ${ }^{29}$ A Korean study of 1688 children aged 10-12 years reported that vitamin D levels and the DMFT index were negatively correlated and, although the correlation was weak, their findings suggest that vitamin D deficiency may be a risk factor for dental caries in this age group. ${ }^{30}$ Another case control study of 1249 Qatari children aged 7-16 years also found a higher prevalence of dental caries among children with a vitamin D deficiency. ${ }^{31}$ 
Table 4 Sex Differences in the Frequency of Food and Beverages Consumed

\begin{tabular}{|c|c|c|c|c|}
\hline \multicolumn{2}{|l|}{ Food/Beverages } & \multirow{2}{*}{$\begin{array}{c}\text { Males N (\%) } \\
60(6.1 \%) \\
90(9.2 \%) \\
450(46.1 \%) \\
377(38.6 \%)\end{array}$} & \multirow{2}{*}{$\begin{array}{c}\text { Females } \mathbf{N} \text { (\%) } \\
64(5.0 \%) \\
78(6.1 \%) \\
537(41.7 \%) \\
609(47.3 \%)\end{array}$} & \multirow{2}{*}{$\frac{\text { P-value }}{0.000^{* *}}$} \\
\hline Biscuits & $\begin{array}{l}\text { Never } \\
\text { Monthly } \\
\text { Weekly } \\
\text { Daily }\end{array}$ & & & \\
\hline Jam & $\begin{array}{l}\text { Never } \\
\text { Monthly } \\
\text { Weekly } \\
\text { Daily }\end{array}$ & $\begin{array}{l}347(35.5 \%) \\
169(17.3 \%) \\
286(29.3 \%) \\
175(17.9 \%)\end{array}$ & $\begin{array}{l}700(54.3 \%) \\
180(14.0 \%) \\
257(20.0 \%) \\
151(11.7 \%)\end{array}$ & $0.000 * *$ \\
\hline Sugar containing chewing gum & $\begin{array}{l}\text { Never } \\
\text { Monthly } \\
\text { Weekly } \\
\text { Daily }\end{array}$ & $\begin{array}{l}124(12.7 \%) \\
61(6.2 \%) \\
372(38.1 \%) \\
420(43.0 \%)\end{array}$ & $\begin{array}{c}256(19.9 \%) \\
102(7.9 \%) \\
328(25.5 \%) \\
602(46.7 \%)\end{array}$ & $0.000^{* *}$ \\
\hline Candies & $\begin{array}{l}\text { Never } \\
\text { Monthly } \\
\text { Weekly } \\
\text { Daily }\end{array}$ & $\begin{array}{c}76(7.8 \%) \\
97(9.9 \%) \\
420(43.0 \%) \\
384(39.3 \%)\end{array}$ & $\begin{array}{c}83(6.4 \%) \\
91(7.1 \%) \\
502(39.0 \%) \\
612(47.5 \%)\end{array}$ & $0.001 *$ \\
\hline Juices & $\begin{array}{l}\text { Never } \\
\text { Monthly } \\
\text { Weekly } \\
\text { Daily }\end{array}$ & $\begin{array}{c}65(6.7 \%) \\
33(3.4 \%) \\
306(31.3 \%) \\
573(58.6 \%)\end{array}$ & $\begin{array}{l}153(11.9 \%) \\
94(7.3 \%) \\
390(30.3 \%) \\
651(50.5 \%)\end{array}$ & $0.000 * *$ \\
\hline Energy drinks & $\begin{array}{l}\text { Never } \\
\text { Monthly } \\
\text { Weekly } \\
\text { Daily }\end{array}$ & $\begin{array}{c}756(77.4 \%) \\
80(8.2 \%) \\
107(11.0 \%) \\
34(3.5 \%)\end{array}$ & $\begin{array}{c}1005(78.0 \%) \\
\text { II } 5(8.9 \%) \\
\text { II } 5(8.9 \%) \\
53(4.1 \%)\end{array}$ & 0.349 \\
\hline Sweetened milk & $\begin{array}{l}\text { Never } \\
\text { Monthly } \\
\text { Weekly } \\
\text { Daily }\end{array}$ & $\begin{array}{l}444(45.4 \%) \\
115(11.8 \%) \\
268(27.4 \%) \\
150(15.4 \%)\end{array}$ & $\begin{array}{l}359(27.9 \%) \\
179(13.9 \%) \\
424(32.9 \%) \\
326(25.3 \%)\end{array}$ & $0.000^{* *}$ \\
\hline Soft drinks & $\begin{array}{l}\text { Never } \\
\text { Monthly } \\
\text { Weekly } \\
\text { Daily }\end{array}$ & $\begin{array}{l}163(16.7 \%) \\
127(13.0 \%) \\
455(46.6 \%) \\
232(23.7 \%)\end{array}$ & $\begin{array}{l}334(25.9 \%) \\
258(20.0 \%) \\
469(36.4 \%) \\
227(17.6 \%)\end{array}$ & $0.000^{* *}$ \\
\hline
\end{tabular}

Notes: Significance test (Chi-square test). $P$ value $<0.05$ is considered statistically significant. *Statistically significant. **Highly significant.

Since adolescence is an important period for developing healthy habits, schools are encouraged to consider promoting milk and dairy consumption on their premises. One study in the KSA found that vitamin D deficiency was influenced by both sun exposure and physical activity; however, children and young adults in the KSA receive significant sunlight exposure, especially during the school day. ${ }^{32}$ The same authors proposed that supplements and their dietary sources should be promoted in schools, even among those with the highest sun exposure and level of physical activity. ${ }^{32}$ Consuming 2 cups $(500 \mathrm{~mL})$ of milk per day has been recommended to maintain optimum vitamin D levels. ${ }^{33}$ A study in Finland, where milk fortified with vitamin D has been mandatory since 2003, found that $91 \%$ of milk drinkers had vitamin D levels at or above $20 \mathrm{ng} / \mathrm{mL}$, which is considered sufficient according to the National Academy of Medicine. ${ }^{34}$

The daily recommended sugar intake limit for adults is approximately 9 teaspoons (tsp) for men and 6 tsp for women, according to the American Heart Association. ${ }^{35}$ A soft drink can $(355 \mathrm{~mL})$ contains $\sim 8$ tsp of sugar. ${ }^{35}$ In the present study, half of the participants $(51 \%)$ consumed approximately $8 \mathrm{tsp}$ of sugar per day $(>300 \mathrm{~mL}$ of soft drinks). Moreover, $41 \%$ and $20 \%$ of the total sample 


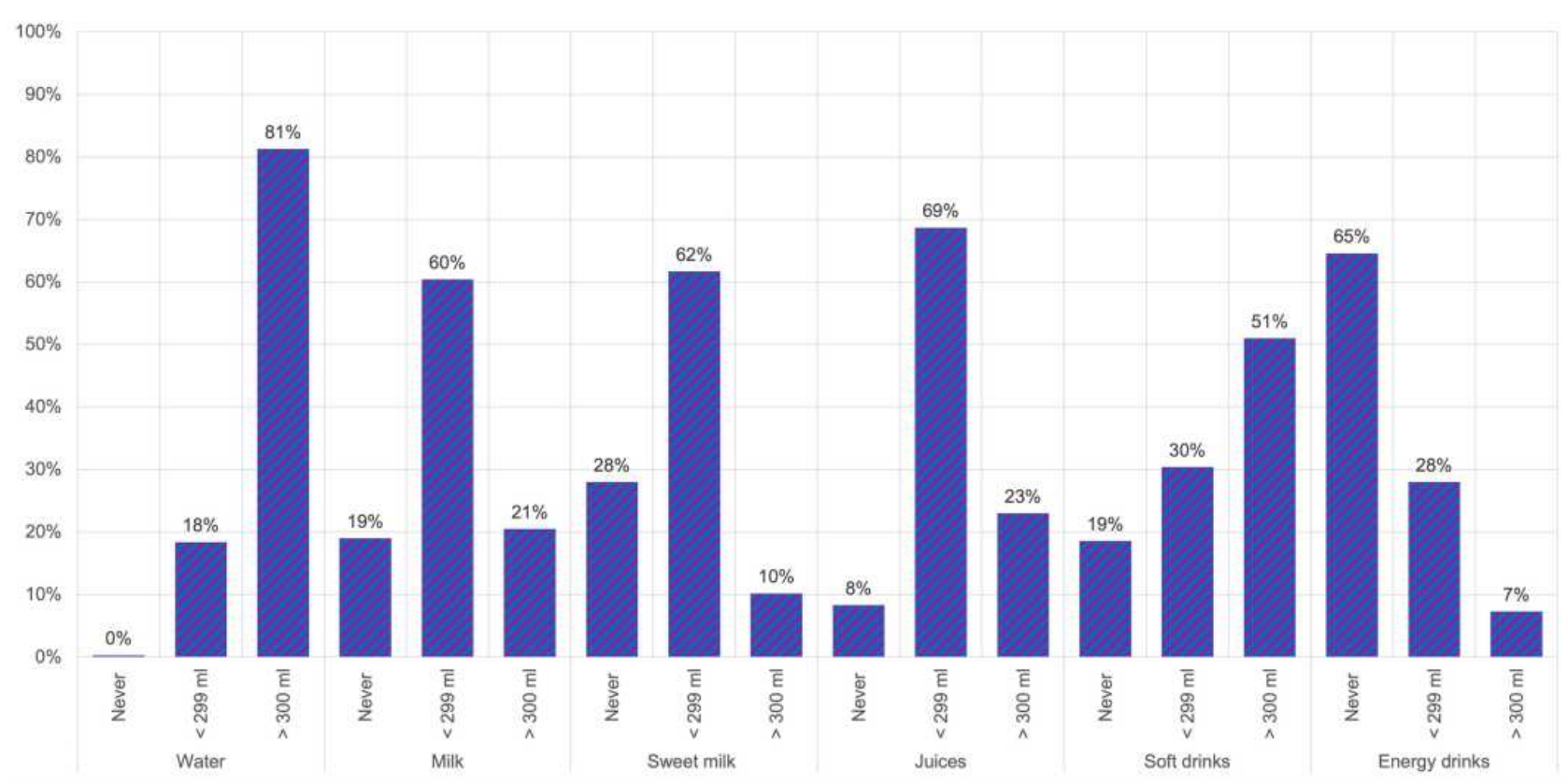

Figure 3 Frequency of the consumed sugary foods among the study sample.

reported weekly and daily consumption of soft drinks, respectively. Such a high amount of added sugar in beverages should be considered a serious public health concern. Our findings are similar to those of a recent national diet and nutrition survey from the United Kingdom, which reported that teenagers (11-18 years) have the highest sugar intake-regardless of its form-compared to other age groups. ${ }^{36}$ The majority of publications about dietary habits categorize beverages and foods according to the presence or absence of free sugars. All carbonated soft drinks, fruit drinks, sports drinks, energy drinks, flavored waters, coffees, teas, hot chocolates, flavored milks or substitutes, meal replacement beverages, protein drinks, smoothies, and drinkable yogurts are classified as sugarsweetened beverages. ${ }^{37,38}$

According to a recent study, the KSA ranks fifth worldwide in the consumption of sugar-sweetened beverages. ${ }^{39}$ Frequent and prolonged exposure to soft drinks increases the risk of tooth erosion, dental caries, and bone fracture. ${ }^{40}$ The WHO, aiming to assist policymakers in reducing total sugar intake, published sugar-restriction guidelines based on the evidence to date indicating that sugar consumption

Table 5 Sex Differences in the Quantity of Beverages Consumed

\begin{tabular}{|c|c|c|c|c|}
\hline \multicolumn{2}{|l|}{ Beverages } & \multirow{2}{*}{$\begin{array}{c}\text { Males N (\%) } \\
45(4.6 \%) \\
584(59.8 \%) \\
348(35.6 \%)\end{array}$} & \multirow{2}{*}{$\begin{array}{c}\text { Females N (\%) } \\
143(11.1 \%) \\
972(75.5 \%) \\
173(13.4 \%)\end{array}$} & \multirow{2}{*}{$\begin{array}{l}\text { P-value } \\
0.000^{* *}\end{array}$} \\
\hline Juices & $\begin{array}{l}\text { Never } \\
<299 \mathrm{~mL} \\
\geq 300 \mathrm{~mL}\end{array}$ & & & \\
\hline Energy drinks & $\begin{array}{l}\text { Never } \\
<299 \mathrm{~mL} \\
\geq 300 \mathrm{~mL}\end{array}$ & $\begin{array}{c}569(58.2 \%) \\
345(35.3 \%) \\
63(6.4 \%)\end{array}$ & $\begin{array}{c}895(69.5 \%) \\
290(22.5 \%) \\
103(8.0 \%)\end{array}$ & $0.000 * *$ \\
\hline Sweetened milk & $\begin{array}{l}\text { Never } \\
<299 \mathrm{~mL} \\
\geq 300 \mathrm{~mL}\end{array}$ & $\begin{array}{l}320(32.8 \%) \\
541(55.4 \%) \\
116(11.9 \%)\end{array}$ & $\begin{array}{c}315(24.5 \%) \\
857(66.5 \%) \\
116(9.0 \%)\end{array}$ & $0.000 * *$ \\
\hline Soft drinks & $\begin{array}{l}\text { Never } \\
<299 \mathrm{~mL} \\
\geq 300 \mathrm{~mL}\end{array}$ & $\begin{array}{l}126(12.9 \%) \\
263(26.9 \%) \\
588(60.2 \%)\end{array}$ & $\begin{array}{l}295(22.9 \%) \\
425(33.0 \%) \\
568(44.1 \%)\end{array}$ & $0.000 * *$ \\
\hline
\end{tabular}

Notes: Significance test (Chi-square test). P value $<0.05$ is considered statistically significant. **Highly significant. 
increases the risk of non-communicable diseases, such as obesity and dental caries. ${ }^{41}$ In response, the government of the KSA has implemented the largest sugar-sweetened beverage tax worldwide by increasing the prices of soft drinks and energy drinks by $50 \%$ and $100 \%$, respectively. ${ }^{39}$

Both the amount of sugar and intake frequency are risk factors for the development of dental caries. Our study revealed that dental caries occur significantly more frequently among females, which is corroborated in other studies. ${ }^{12,42}$ Researchers often allude to females typically having more "filled" teeth, which can result in an overall higher DMFT index. Dental caries has been associated with a variety of systemic diseases, such as head and neck cancer, nutritional disturbances, abnormal growth in children, cardiovascular diseases, autoimmune diseases, and kidney diseases. ${ }^{43}$

High consumption of a sugary diet has been listed as a risk factor for gingivitis. ${ }^{44}$ The reported association between a sugary diet and gingivitis has also been explained by the deposition of plaque on surrounding tooth surfaces, thereby decreasing the $\mathrm{pH}$ and leading to more bacterial growth that causes gingival inflammation. ${ }^{44}$ In the current study, males were found to have more plaque accumulation, gingival problems, and a greater consumption of sugary drinks. Plaque accumulation and gingival inflammation reflect poor oral hygiene practices, which was apparent in the current study among males, given that only $28.9 \%$ brushed their teeth twice daily; similar to the rates reported in other studies. ${ }^{10}$ Gingival and periodontal diseases are linked to many systemic diseases, including diabetes, rheumatoid arthritis, cerebrovascular and cardiovascular diseases, and adverse pregnancy outcomes. ${ }^{45}$

This study was conducted among school children during regular school hours, highlighting the opportunity of utilizing schools as an effective venue for developing and maintaining healthy lifestyle practices. Prevention programs carried out through schools have been well established as effective at promoting oral health and healthy diets through regular screening and oral hygiene education. ${ }^{46,47}$

Our study was subject to some limitations, one of which was its reliance on students' self-reports. One disadvantage of interview-based questionnaires is that participants might modify their responses in order to be viewed more favorably by the interviewers (ie, social desirability bias). Recall bias cannot be excluded when investigating frequencies and quantities of foods and drinks. A major disadvantage of the FFQ is that it does fails to provide absolute nutritional values. Also, sugar intake could not be estimated from all drinks and sweetened foods, given the overwhelming variety of such products in the Saudi market. Furthermore, the cross-sectional nature of our study can only provide associations, but not causations.

Despite these limitations, our study used a large sample and a random sampling method, which allows for better generalizability of the findings. Additionally, our study relied on the FFQ and a calibrated oral health examination, which makes the current findings valid and reliable, and which permits a comprehensive evaluation of sex differences in sugary diet intake. The finding of this study can help tailor interventional and preventive programs to target all-male or all-female schools.

\section{Conclusion}

The frequency and quantity of consumed sugary foods and drinks was found to be higher in males. Dental caries was found more commonly among females, but males had more plaque accumulation and gingival problems. Optimization of individuals' health is the goal of both the medical and dental professions; therefore, further studies are needed to assess sex differences with a more holistic approach. In the same context, policymakers can utilize the common risk approach to control sugar consumption, as well as acknowledge sex differences when developing preventive programs.

\section{Disclosure}

The authors report no conflicts of interest in this work and had received no specific grant from any funding agency in the public, commercial, or not-for-profit sectors.

\section{References}

1. Marriott BP, Hunt KJ, Malek AM, Newman JC. Trends in intake of energy and total sugar from sugar-sweetened beverages in the United States among children and adults, NHANES 2003-2016. Nutrients. 2019;11(9):2004. doi:10.3390/nu11092004

2. Al-Hussaini A, Bashir MS, Khormi M, et al. Overweight and obesity among Saudi children and adolescents: where do we stand today? Saudi J Gastroenterol. 2019;25(4):229-235. doi:10.4103/sjg.SJG_617_18

3. Carbone S, Billingsley HE, Lavie CJ. The effects of dietary sugars on cardiovascular disease and cardiovascular disease-related mortality: finding the sweet spot. Mayo Clin Proc. 2019;94(12):2375-2377. doi:10.1016/j.mayocp.2019.10.017

4. Dörfer C, Benz C, Aida J, Campard G. The relationship of oral health with general health and NCDs: a brief review. Int Dent $J$. 2017;67 (Suppl 2):14-18. doi:10.1111/idj.12360

5. Mauri-Obradors E, Estrugo-Devesa A, Jané-Salas E, Viñas M, LópezLópez J. Oral manifestations of diabetes mellitus. a systematic review. Med Oral Patol Oral Cir Bucal. 2017;22(5):e586-e594. doi:10.4317/ medoral.21655 
6. Lavigne SE, Forrest JL. An umbrella review of systematic reviews of the evidence of a causal relationship between periodontal disease and adverse pregnancy outcomes: a position paper from the Canadian dental hygienists association. Can J Dent Hyg. 2020;54(2):92-100.

7. World Health Organization. Sugars and dental caries; 2017. Available from: https://www.who.int/oral_health/publications/sugars-dentalcaries-keyfacts/en/. Accessed November 19, 2019.

8. Mathur VP, Dhillon JK. Dental caries: a disease which needs attention. Indian J Pediatr. 2018;85(3):202-206. doi:10.1007/ s12098-017-2381-6

9. Moynihan P, Petersen PE. Diet, nutrition and the prevention of dental diseases. Public Health Nutr. 2004;7(1A):201-226. doi:10.1079/ PHN2003589

10. Liu Y, Yu Y, Nickel JC, et al. Gender differences in the association of periodontitis and type 2 diabetes. Int Dent J. 2018;68(6):433-440. doi:10.1111/idj.12399

11. Kulhavá L, Eckhardt A, Pataridis S, Bartoš M, Foltán R, Mikšík I. Differences of saliva composition in relation to tooth decay and gender. Folia Biologica. 2018;64(5/6):195-203.

12. Lukacs JR. Gender differences in oral health in South Asia: metadata imply multifactorial biological and cultural causes. Am J Hum Biol. 2011;23(3):398-411. doi:10.1002/ajhb.21164

13. Tudoroniu C, Popa M, Iacob SM, Pop AL, Năsui BA. Correlation of caries prevalence, oral health behavior and sweets nutritional habits among 10 to 19-year-old Cluj-Napoca Romanian adolescents. Int J Environ Res Public Health. 2020;17(18):6923. doi:10.3390/ ijerph 17186923

14. Hamasha AA-H, Alshehri A, Alshubaiki A, Alssafi F, Alamam H, Alshunaiber R. Gender specific oral health beliefs and behaviors among adult patients attending king Abdulaziz Medical City in Riyadh. Saudi Dent J. 2018;30(3):226-231. doi:10.1016/j. sdentj.2018.05.003

15. Ashi H, Campus G, Berteus Forslund H, Hafiz W, Ahmed N, Lingström $P$. The influence of sweet taste perception on dietary intake in relation to dental caries and BMI in Saudi Arabian schoolchildren. Int J Dent. 2017;2017:4262053. doi:10.1155/2017/4262053

16. World Health Organization. Vienna statement on investing in women's health in the countries of central and eastern Europe; 1994. Available from: https://www.euro.who.int/en/publications/policy-documents /vienna-statement-on-investing-in-womens-health-in-the-countries-ofcentral-and-eastern-europe,-1994. Accessed March 7, 2020.

17. Alissa EM, Bahjri SM, Al-Ama N, Ahmed WH, Starkey B, Ferns GA. Dietary vitamin A may be a cardiovascular risk factor in a Saudi population. Asia Pac J Clin Nutr. 2005;14(2):137-144.

18. Alissa EM, Alama NA. Nutritional intake and cardiovascular risk factors in Saudi subjects with different degrees of atherosclerosis: a case control study. J Nutri Med Diet Care. 2015;1(2):1-9. doi: $10.23937 / 2572-3278.1510008$

19. Washi SA, Ageib MB. Poor diet quality and food habits are related to impaired nutritional status in 13- to 18-year-old adolescents in Jeddah. Nutr Res. 2010;30(8):527-534. doi:10.1016/j. nutres.2010.07.002

20. World Health Organization. Oral health surveys: basic methods; 2013. Available from: https://www.who.int/oral_health/publications/ 9789241548649/en/. Accessed October 20, 2019.

21. Löe $H$. The gingival index, the plaque index and the retention index systems. $J$ Periodontol. 1967;38(6):610-616. doi:10.1902/ jop.1967.38.6_part2.610

22. Jomaa L, Hamamji S, Kharroubi S, Diab-El-Harakeh M, Chokor FA, Nasreddine L. Dietary intakes, sources, and determinants of free sugars amongst Lebanese children and adolescents: findings from two national surveys. Eur J Nutr. 2021.

23. Abdella HM, El Farssi HO, Broom DR, Hadden DA, Dalton CF. Eating behaviours and food cravings; influence of age, sex, BMI and FTO genotype. Nutrients. 2019;11(2):377. doi:10.3390/nu11020377
24. Al-Hazzaa HM, Al-Sobayel HI, Abahussain NA, Qahwaji DM, Alahmadi MA, Musaiger AO. Association of dietary habits with levels of physical activity and screen time among adolescents living in Saudi Arabia. J Hum Nutr Diet. 2014;27(Suppl 2):204-213. doi:10.1111/jhn. 12147

25. Bello LL, Al-Hammad N. Pattern of fluid consumption in a sample of Saudi Arabian adolescents aged 12-13 years. Int J Paediatr Dent. 2006;16(3):168-173. doi:10.1111/j.1365-263X.2006.00715.x

26. Missagia SV, Oliveira SR, Rezende DC. Beauty and the beast: gender differences in food-related behavior. Revista Brasileira De Marketing. 2013;12(1):149-165. doi:10.5585/remark.v12i1.2441

27. Gopinath B, Flood VM, Burlutsky G, Louie JC, Baur LA, Mitchell P. Pattern and predictors of dairy consumption during adolescence. Asia Pac J Clin Nutr. 2014;23(4):612-618. doi:10.6133/ apjen.2014.23.4.05

28. Al-Alyani H, Al-Turki HA, Al-Essa ON, Alani FM, Sadat-Ali M. Vitamin D deficiency in Saudi Arabians: a reality or simply hype: a meta-analysis (2008-2015). J Family Community Med. 2018;25 (1):1-4. doi:10.4103/jfcm.JFCM_73_17

29. Khammissa RA, Ballyram R, Jadwat Y, Fourie J, Lemmer J, Feller L. Vitamin D deficiency as it relates to oral immunity and chronic periodontitis. Int J Dent. 2018;2018:7315797. doi:10.1155/2018/ 7315797

30. Kim IJ, Lee HS, Ju HJ, Na JY, Oh HW. A cross-sectional study on the association between vitamin $\mathrm{D}$ levels and caries in the permanent dentition of Korean children. BMC Oral Health. 2018;18(1):43. doi:10.1186/s12903-018-0505-7

31. Bener A, Al Darwish MS, Hoffmann GF. Vitamin D deficiency and risk of dental caries among young children: a public health problem. Indian J Oral Sci. 2013;4(2):75-82. doi:10.4103/0976-6944.119937

32. Al-Othman A, Al-Musharaf S, Al-Daghri NM, et al. Effect of physical activity and sun exposure on vitamin D status of Saudi children and adolescents. BMC Pediatr. 2012;12:92. doi:10.1186/1471-2431-12-92

33. Maguire JL, Lebovic G, Kandasamy S, et al. The relationship between cow's milk and stores of vitamin $\mathrm{D}$ and iron in early childhood. Pediatrics. 2013;131(1):144-151. doi:10.1542/peds.2012-1793

34. Jääskeläinen T, Itkonen ST, Lundqvist A, et al. The positive impact of general vitamin D food fortification policy on vitamin D status in a representative adult Finnish population: evidence from an 11-y follow-up based on standardized 25-hydroxyvitamin D data. Am J Clin Nutr. 2017;105(6):1512-1520. doi:10.3945/ajen.116.151415

35. Johnson RK, Appel LJ, Brands M, et al. Dietary sugars intake and cardiovascular health: a scientific statement from the American Heart Association. Circulation. 2009;120(11):1011-1020. doi:10.1161/ CIRCULATIONAHA.109.192627

36. Amoutzopoulos B, Steer T, Roberts C, Collins D, Page P. Free and added sugar consumption and adherence to guidelines: the UK national diet and nutrition survey (2014/15-2015/16). Nutrients. 2020;12(2):393. doi:10.3390/nu12020393

37. Islam MA, Al-Karasneh AF, Hussain AB, et al. Assessment of beverage consumption by young adults in Saudi Arabia. Saudi Pharm J. 2020;28(12):1635-1647. doi:10.1016/j.jsps.2020.10.010

38. Jones AC, Kirkpatrick SI, Hammond D. Beverage consumption and energy intake among Canadians: analyses of 2004 and 2015 national dietary intake data. Nutr J. 2019;18(1):60. doi:10.1186/s12937-0190488-5

39. Alsukait R, Bleich S, Wilde P, Singh G, Folta S. Sugary drink excise tax policy process and implementation: case study from Saudi Arabia. Food Policy. 2020;90:101789. doi:10.1016/j.foodpol.2019.101789

40. Chen L, Liu R, Zhao Y, Shi Z. High consumption of soft drinks is associated with an increased risk of fracture: a 7-year follow-up study. Nutrients. 2020;12(2):530. doi:10.3390/nu12020530

41. World Health Organization. Guideline: sugars intake for adults and children; 2015. Available from: https://www.who.int/nutrition/publica tions/guidelines/sugars_intake/en/. Accessed December 11, 2019. 
42. Meyer BD, Lee JY. The confluence of sugar, dental caries, and health policy. $J$ Dent Res. 2015;94(10):1338-1340. doi:10.1177/ 0022034515598958

43. Ling Z, Tao H. Dental caries and systemic diseases. In: Xuedong Z, editor. Dental Caries Principles and Management. 1 st ed. Heidelberg: Springer; 2015:129-155.

44. Asawa K, Sen N, Bhat N, Tak M, Sultane P, Patil V. Association of sugary foods and drinks consumption with behavioral risk and oral health status of 12- and 15-year-old Indian school children. $J$ Educ Health Promot. 2018;7:19. doi:10.4103/jehp.jehp_53_17
45. Seitz MW, Listl S, Bartols A, et al. Current knowledge on correlations between highly prevalent dental conditions and chronic diseases: an umbrella review. Prev Chronic Dis. 2019;16:132. doi:10.5888/pcd16.180641

46. Vozza I, Capasso F, Calcagnile F, et al. School-age dental screening: oral health and eating habits. Clin Ter. 2019;170(1):36-40.

47. Mazur M, Bietolini S, Bellardini D, et al. Oral health in a cohort of individuals on a plant-based diet: a pilot study. Clin Ter. 2020;171 (2):142-148.

\section{Publish your work in this journal}

Patient Preference and Adherence is an international, peer-reviewed, open access journal that focusing on the growing importance of patient preference and adherence throughout the therapeutic continuum. Patient satisfaction, acceptability, quality of life, compliance, persistence and their role in developing new therapeutic modalities and compounds to optimize clinical outcomes for existing disease states are major areas of interest for the journal. This journal has been accepted for indexing on PubMed Central. The manuscript management system is completely online and includes a very quick and fair peer-review system, which is all easy to use. Visit http:// www.dovepress.com/testimonials.php to read real quotes from published authors. 